\title{
THE CORRELATION BETWEEN BISPECTRAL INDEX AND ELECTROMYOGRAPHIC ACTIVITY IN POST-CARDIAC ARREST PATIENTS AND THE ROLE OF NEUROMUSCULAR BLOCKERS
}

\author{
C. Drieskens, W. Eertmans, R. Heylen, P. Vanelderen, D. Mesotten, C. De Deyne \\ Department of Medicine and Life Sciences, Hasselt University, Diepenbeek, Belgium \\ Department of Anesthesiology, Intensive Care, Emergency Medicine and Pain Therapy, ZOL Genk, Belgium
}

\section{INTRODUCTION}

In all previous studies, exploring the prognostic role of bispectral index (BIS) after out-of-hospital cardiac arrest (OHCA), neuromuscular blockers (NMB) were administered continuously in all patients to minimize electromyographic (EMG) activity interference. Our study cohort, however, was treated according to current guidelines, limiting NMB use to only patients experiencing shivering.

\section{AIM}

This cohort study aimed to determine the correlation between EMG activity and BIS in post-CA patients.

\section{METHODS}

- After admission to the ICU, BIS monitoring was initiated in 77 successfully resuscitated OHCA patients using BIS VISTA ${ }^{\mathrm{TM}}$ device (Aspect Medical Systems, Inc. Norwood, USA).

- Targeted temperature management (TTM) at $33^{\circ} \mathrm{C}$ was used (i.e. 24 hours), followed by a rewarming phase of 12 hours

- Cisatracurium was only administered to patients who experienced shivering

- Mean BIS and EMG values were calculated and used for data analysis Statistics:

- Regression curves were fitted between mean EMG and BIS values below and above 30 (including the calculation of the Pearson correlation coefficient) - Two groups: Treatment without NMB - Treatment with NMB.

\section{RESULTS}

Table 1. Baseline characteristics according to neurological outcome.

\begin{tabular}{|c|c|c|c|}
\hline Characteristic & $\begin{array}{c}\text { Good neurological } \\
\text { outcome } \\
(\mathrm{N}=38)\end{array}$ & $\begin{array}{l}\text { Poor neurological out- } \\
\begin{array}{c}\text { come } \\
(\mathrm{N}=39)\end{array}\end{array}$ & $\mathbf{P}$ \\
\hline Age & $67 \pm 13$ & $61 \pm 13$ & 0.034 \\
\hline Male & $31(82)$ & $31(80)$ & 0.817 \\
\hline Shockable initial rhythm & $33(87)$ & $20(56)$ & 0.003 \\
\hline Witnessed arrest & $34(92)$ & $33(87)$ & 0.479 \\
\hline Time Emergency call - ROSC (min) & $28 \pm 19$ & $32 \pm 15$ & 0.388 \\
\hline Percutaneous Coronary Intervention & $27(71)$ & $17(44)$ & 0.015 \\
\hline Time to target temperature (min) & $176 \pm 134$ & $184 \pm 158$ & 0.820 \\
\hline
\end{tabular}

Data are shown as mean \pm SD and $\mathrm{n}(\%)$.

ROSC $=$ Return of spontaneous circulation.

Table 2. Baseline characteristics according to neuromuscular blockage use.

\begin{tabular}{lccc}
\hline Characteristic & No NMB received & NMB received & \\
& $\mathbf{( N = 3 3 )}$ & $\mathbf{( N = 4 4 )}$ & P \\
\hline Poor neurological outcome & $15(45)$ & $24(54)$ & 0.494 \\
Age & $67 \pm 11$ & $61 \pm 14$ & $\mathbf{0 . 0 3 6}$ \\
Male & $30(91)$ & $32(72)$ & 0.079 \\
Shockable initial Rhythm & $20(61)$ & $33(75)$ & 0.301 \\
Witnessed arrest & $27(82)$ & $40(91)$ & 0.275 \\
Time Emergency call - ROSC (min) & $27 \pm 14$ & $32 \pm 19$ & 0.315 \\
Percutaneous Coronary Intervention & $16(48)$ & $28(63)$ & 0.245 \\
Time to target temperature (min) & $172 \pm 120$ & $187 \pm 165$ & 0.677 \\
\hline
\end{tabular}

Data are shown as mean \pm SD and $\mathrm{n}(\%)$.

$\mathrm{NMB}=$ Neuromuscular blocker; $\mathrm{ROSC}=$ Return of spontaneous circulation.
Figure 1. Correlation between mean BIS and EMG.
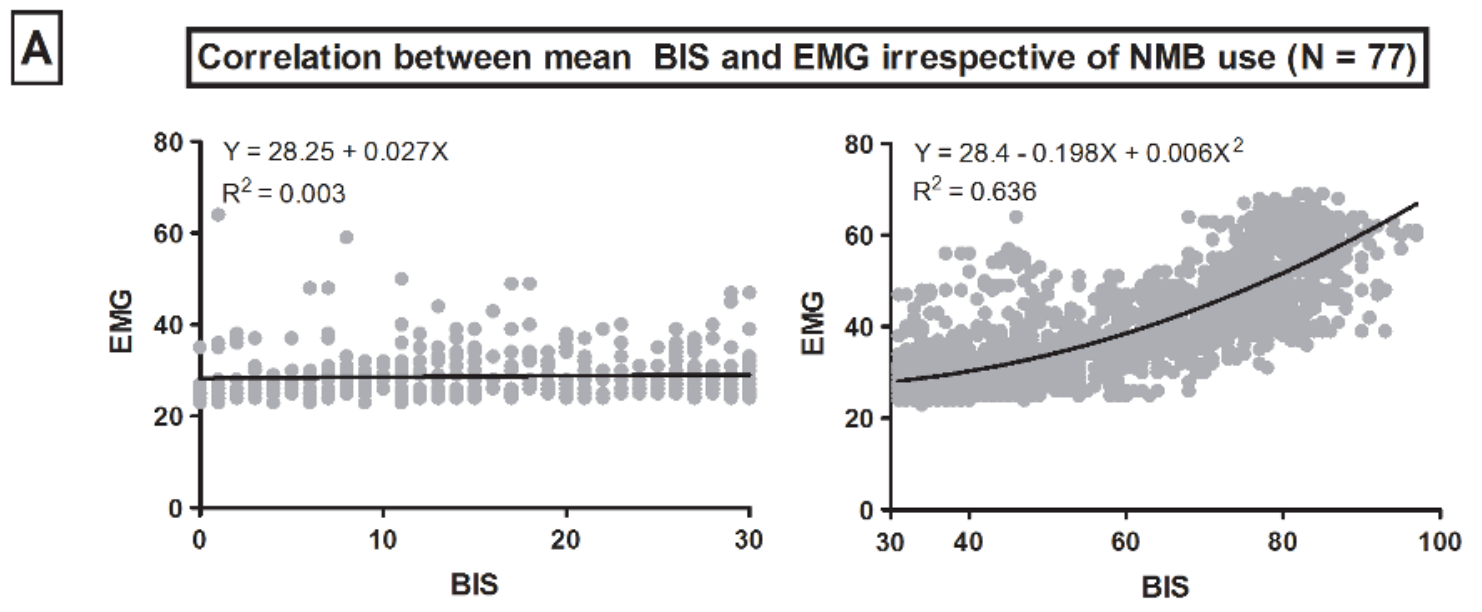

$B$ Correlation between mean BIS and EMG in patients without NMB $(\mathrm{N}=33)$
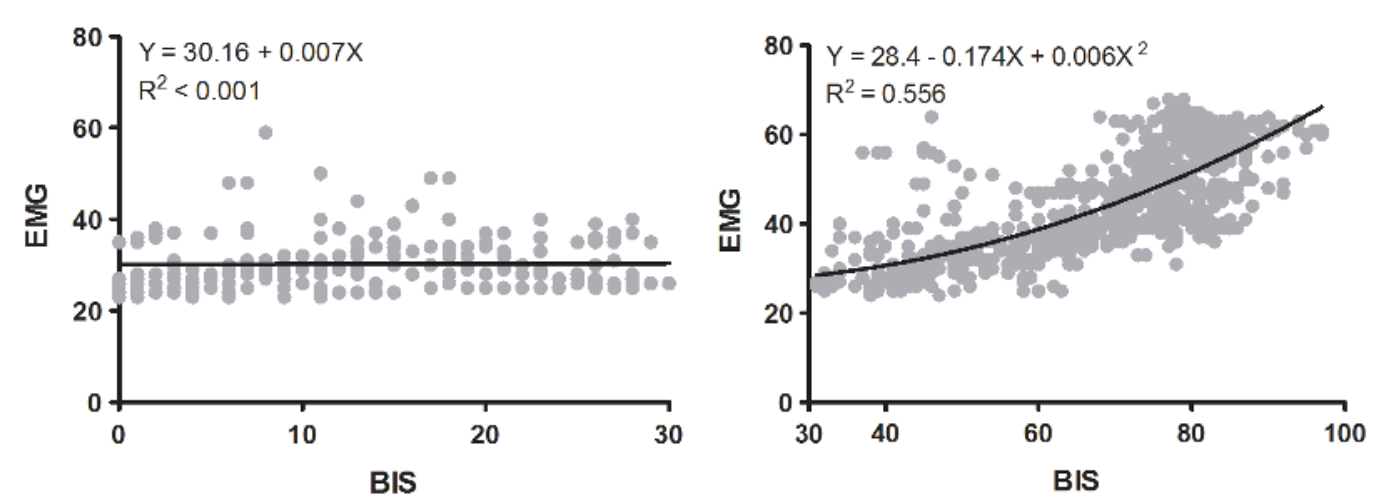

\section{CONCLUSIONS}

This analysis implied that EMG interference below a BIS of 30 is rather negligible even in patients who were not treated with NMB. As such, BIS values below 30 might be usable to assist with poor outcome prognostication in OHCA patients, without the need for continuous administration of NMB. 